\title{
FAILED BACK SURGERY SYNDROME
}

\section{Casuistic and etiology}

\author{
Flávio Freinkel Rodrigues', Diego Cassol Dozza, \\ Claudio Russio de Oliveira², Ricardo Gomes de Castro ${ }^{2}$
}

\begin{abstract}
ASTRACT - Objective: To report our data of cases of failed back surgery syndrome (FBSS) and surgical and nonsurgical etiologies. Method: The medical charts of 121 patients submitted to laminectomy, hemilaminectomy combined with discectomy and/or foraminotomy between January 1997 and October 2004 in the Instituto of Neurologia Deolindo Couto were reviewed. The inclusion criterion was does not improve or the symptoms return after the surgery and with a minimum of three medical consultations with adequate investigation for the diagnosis. The patients had been divided in three main pre-surgical diagnosis: herniated disc, lumbar stenosis and the association of these. Results: From the 121 patients submitted to spine surgical intervention, $47(38.8 \%)$ had presented criteria for the FBSS. Among the 26 patients who had presented operative diagnosis of lumbar stenosis, $8(30.7 \%)$ had presented FBSS; of the 83 with disc herniation, $31(37.3 \%)$ had the syndrome; and the 12 patients with lumbar stenosis associated with disc herniation, 7 (58.3\%) had failure of the back surgery. Conclusion: The failure of back surgery remains a challenge for the surgeons. There is an incessant search for the causes and the action mechanisms of this syndrome and the best method of treatment.
\end{abstract}

KEY WORDS: failed back surgery syndrome, back pain, spinal stenosis, recurrent disc herniation, discectomy, epidural fibrosis.

\section{Síndrome pós-laminectomia: casuística e etiologia}

RESUMO - Objetivo: Relatar nossos dados sobre a síndrome pós-laminectomia (SPL) e as causas cirúrgicas e não-cirúrgicas. Método: Foram revisados 121 prontuários de pacientes submetidos a laminectomia, hemilaminectomia combinadas com discectomia e/ou foraminotomia realizadas no Instituto de Neurologia Deolindo Couto entre janeiro de 1997 e outubro de 2004. Resultados: Dos 121 pacientes que sofreram intervenção cirúrgica lombar, 47 (38,8\%) apresentaram critérios para a SPL. Dos 26 pacientes que apresentaram diagnóstico pré-operatório de estenose lombar, $8(30,7 \%)$ apresentaram SPL; dos 83 com hérnia de disco, $31(37,3 \%)$ tiveram a síndrome; e dos 12 pacientes com estenose lombar associada com hérnia de disco, $7(58,3 \%)$ tiveram a SPL. Conclusão: A síndrome pós-laminectomia permanece um desafio para os cirurgiões. Há uma busca incessante pelas causas e os mecanismos de ação desta síndrome e o melhor método de tratamento.

PALAVRAS-CHAVE: síndrome pós-laminectomia, lombalgia, estenose de canal lombar, hérnia de disco recorrente, discectomia, fibrose epidural.

Failed back surgery syndrome (FBSS) is an imprecise term used to categorize a heterogeneous group of cause to residual symptoms after back surgical treatment. It is not a definitive diagnosis and it is considered a syndrome because it has many explanatory etiologies as clinical as surgical ${ }^{1-5}$. The main factor is to delineate its cause through the evaluation of clinical history, physical examination and psycho-part- ner-economic profile, since the treatment is specific and individualized. Despite the large number of revisions on the subject, there is still lack of epidemiologic studies to define the illnesses. Amongst the few existing, there is a reportion the incidence of 2000 cases in the United Kingdom 6 . Currently, through the complementary methods the cause of FBSS can be elucidated in over $90 \%$ of patients. There is a great

Instituto de Neurologia Deolindo Couto (INDC), Universidade Federal do Rio de Janeiro, Rio de Janeiro RJ, Brasil (UFRJ): ${ }^{1}$ Professor Doutor da Faculdade de Medicina da UFRJ, Chefe do Serviço de Neurocirurgia do INDC-UFRJ; ${ }^{2}$ Médico-Residente de Neurocirurgia INDC-UFRJ.

Received 15 December 2005, received in final form 19 May 2006. Accepted 14 June 2006.

Dr. Flávio F. Rodrigues - Rua Buarque de Macedo 14 / 606 - 22220-030 Rio de Janeiro RJ - Brasil. E-mail: dcdozza@yahoo.com.br 
Table 1. Surgical and nonsurgical causes of FBSS.

\begin{tabular}{ll}
\hline Surgical & Nonsurgical \\
\hline Canal stenosis & Epidural fibrosis \\
Internal disc disruption & Degenerative disc \\
Retained/recurrent disc & Radiculopathy \\
Spondylolisthesis & Facet syndrome \\
Synovial cyst & Sacroiliac joint syndrome \\
Vascular claudication & Reflex sympathetic dystrophy \\
Instability & Arachnoiditis \\
Pseudomeningocele & Psychological \\
Pseudarthrosis & Unknown \\
\hline
\end{tabular}

discussion around of the division in surgical and nonsurgical causes (Table 1), being that some authors question this method. There is difficult in establishing definitions of nonsurgical causes because exist variable criteria in the medical concepts, what occurs probably for differences in specialty medical, practice setting, cultural and patient population'. Already in the surgical area, bigger precision in the terms occurs, since has possibility of the use of complementary examinations that allow greater accuracy of the diagnosis. A cause considered for the majority of the authors is the imperfection in the adequate choice of the treatment for determined disease, due the incorrect or incomplete diagnosis before surgery, or the type of surgery performed was not appropriate. Another factor that has great importance is the psychic profile of the patient. Long ${ }^{2}$ in his study found up to $15 \%$ of psychiatric alteration in the initial diagnosis, being the most frequent: depression, anxiety and abuse of chemical substances, and up to $70 \%$ in those without postoperative improvement. Disability in these patients appears to relate to psychologic dysfunction rather than the physical abnormalities and, then, imperfection in the procedure occurs and some times have necessity of new surgery ${ }^{7}$. Litigious processes also contribute for the imperfection in the treatment and the improvement does not occur until it has solution.

In the epidemiologic studies revised, the main causes are foraminal stenosis, internal disc disruption, pseudarthrosis and neuropathic pain, which together, correspond more than $70 \%{ }^{1-4}$. A practical method is divide the patients into those with predominance of lumbar pain versus predominance of leg pain, this allows to establish a logical sequence that will be used to carry the complementary examinations. Lumbar pain can occur on disc disease, instability, pseudarthrosis. Pain initially in the inferior member can occur in canal stenosis, recurrent or residual disc hernia- tion or for neuropathic pain ${ }^{3}$. To establish a correct diagnosis it is necessary to understand which structure is causing pain and then to apply the appropriate treatment. Pain can be caused by practically all the structures of the vertebral column: intervertebral disc, zygapophyseal joint, muscles, ligaments, sacroiliac joint ${ }^{2,8,9}$. Each one occurring for proper mechanisms as nerve root compression, arthritic joints, instability, disc degeneration, myositis, fasciitis, bursitis and in the postoperative patient the occurrence of arachnoiditis and fibrosis ${ }^{10}$. There is much discussion about the fibrosis, since many patients develop it after the surgery but nor all present pain and still lack a study that demonstrates the percentage of those with fibrosis and painful process. With the use of devices to fix the column, new causes of pain had appeared. These procedures can cause compression of nervous root, bad setting with instability and pseudarthrosis. The failed of patient selection, led to the surgical imperfection and, sometimes, a new procedure is necessary ${ }^{11}$. Also surgical imperfections occur because of bad indication of the procedure with incomplete accomplishment and complications (arachnoiditis, fibrosis, injury of the root, infection of the discal space, pseudomeningocele, instability). Already the prognostics factors include the absence of litigious process and good bone fusing ${ }^{12,13}$.

We report our experience on FBSS.

\section{METHOD}

Retrospective study based on the revision of a series of patients submitted to spinal surgery and followed in the Instituto of Neurologia Deolindo Couto. Also a revision of literature was carried and the results had been compared. This study was approved by the ethic commission of the institution.

The medical charts of 121 patients submitted to laminectomy, hemilaminectomy combined with discectomy and/or foraminotomy between January 1997 and October 2004 were reviewed in our service. From these, 47 (38.8\%) had presented criteria for the FBSS. There were 27 men and 20 women. The age average was 46.3 years (range $22-75$ ). The inclusion criterion was does not improve or the return of the symptoms after the surgery and with a minimum of three medical consultation with adequate investigation for the diagnosis, those that had presented occasional back pain and without an enough number of follow-up had been excluded. The patients had been divided in three main pre-surgical diagnosis: herniated disc, lumbar stenosis and the association of these. Almost all had been carried through computed tomography (CT), X-rays, magnetic resonance imaging (MRI) and some had been complemented by electroneuromyography (ENMG). The diagnosis was based on clinical history, physical examination and complementary examinations. The patients with recurrent herniation or retained disc had been grouped in an only group. Twenty 
Table 2. The absolute number and percentage of each diagnosis with respective primary diagnosis.

\begin{tabular}{|c|c|c|c|}
\hline Diagnosis & Herniated disc & Stenosis & Stenosis + HNP \\
\hline HNP & $12(25.5 \%)$ & $5(10.6 \%)$ & $3(6.3 \%)$ \\
\hline Foraminal stenosis & $1(2.1 \%)$ & $1(2.1 \%)$ & \\
\hline Fibrosis & $7(14.9 \%)$ & & \\
\hline PDDD & $4(8.5 \%)$ & $1(2.1 \%)$ & \\
\hline Pseudarthrosis & & $1(2.1 \%)$ & \\
\hline Radiculopathy & $2(4.2 \%)$ & & \\
\hline Psychological & & $1(2.1 \%)$ & \\
\hline Arachnoiditis & $1(2.1 \%)$ & & \\
\hline Stenosis plus HNP & $1(2.1 \%)$ & & $1(2.1 \%)$ \\
\hline Stenosis plus HNP plus instability & & & $1(2.1 \%)$ \\
\hline Stenosis plus fibrosis & & & $1(2.1 \%)$ \\
\hline Unknown & $3(6.3 \%)$ & & $1(2.1 \%)$ \\
\hline
\end{tabular}

eight patients had underwent a single surgery (laminectomy, hemilaminectomy combined with discectomy and/or foraminotomy) that resulted in the FBSS and 19 patients had been submitted more than one intervention, but the diagnosis was considered with the first surgical failure.

\section{RESULTS}

Of the 121 patients submitted to surgical intervention, 47 (38.8\%) had presented criteria for the FBSS. There were 28 patients that underwent one surgery, 17 with two, 1 with three and 1 that underwent five surgeries.

Of the 26 patients who had presented lumbar stenosis diagnosis before surgical, 8 (30.7\%) had presented FBSS; of the 83 with discal hernia, 31 (37.3\%) had the syndrome; e of the 12 patients with lumbar stenosis associate with discal hernia, 7 (58.3\%) had fail of the back surgery. Only four patients had been without diagnosis (8.5\%).

The diagnosis of the FBSS most frequent had been recurrent or residual disc herniation, canal stenosis, fibrosis and internal disc disruption. In the patients with more than one surgery, to each new intervention generally had a new diagnosis in which retained/ herniated recurrent disc herniation was the most frequent followed by epidural fibrosis, canal stenosis and arachnoiditis. In Table 2 are indicated the etiologies in relation to each previous alteration in all patients after the first surgery.

\section{DISCUSSION}

In this study the major cause for the FBSS was the surgery for herniated disc (discectomy and hemilaminectomy) and occurred mainly in the first years of the revision, when it had difficulty with the complementary examinations. In this way, clinical history must be detailed and to contain the previous problems to the surgery. Attention is necessary in the alterations of the personality and association of diagnosis. Pain has been detailed with the localization, characteristic, type, irradiation, aggravations and relief factors. The predominance of lumbar pain suggests local problem while leg pain with sciatica characteristics suggests irritation of the root. The importance that the patient gives to its pain and the narrative are important factors for psychiatric alterations.

The physical examination must be initiated by examining the scar surgical that many times is responsible for sensitive alteration, as well as signals of myositis. The movements amplitude can suggest canal stenosis, when occurs pain to the hyperextension. The examination of the hip can disclose local injury that also cause sciatic. It must be carried through the complete neurological examination with attention to the force and reflex. Another important data is to observe the behavior of the patient during all the maneuvers and if the complaints agree with the findings of the exam ${ }^{14}$.

In our series the percentage of discal hernia as FBSS cause was 37\%, greater that the presented for other studies, where the average was 7 to $33 \%{ }^{1-3}$, as well as lesser occurrence of canal stenosis and greater of epidural fibrosis. It does not have how to compare adequately since in these studies the pre-surgical diagnostic has been not related and, thus, we cannot survey if it has some relation between the type of surgery carried, with the subsequent etiology 


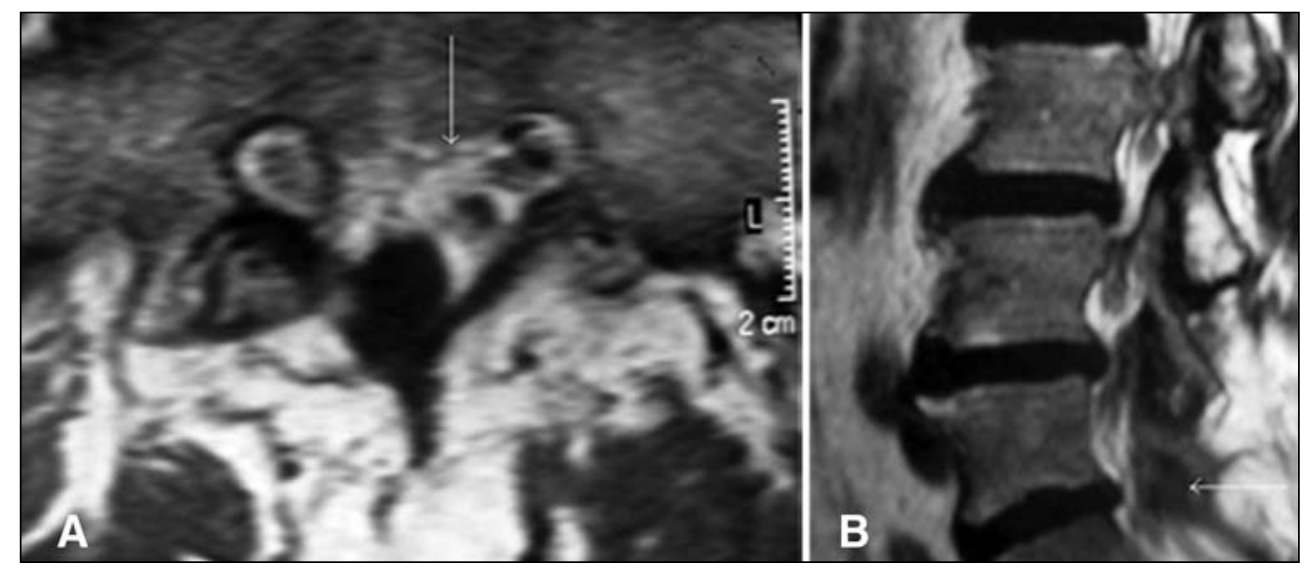

Fig 1. Axial MRI (A) and sagittal (B) with contrast showing epidural fibrosis.

found. We thought that must have a correlation with the diagnosis and the type of surgery carried and future fail back syndrome. Fibrosis (Figure) also remains questionable; therefore it does not have safe diagnostic method that allows to affirm which alteration is causing pain in the patient, mainly when other etiologies can be involved and associates. This remains as key point for the precise indication of the procedure.

The average duration of symptom relief was 4 months, with a range of 0 to 5 years. In lumbar stenosis the symptoms recurrented in average of 3 months, in the discal herniation it had a bimodal distribution, being of 2 to 3 months initially and another peak between 1 and 2 years. It was indicated in other studies as of Slipman ${ }^{1}$ in which stenosis spinal returned in six months in $57 \%$ of the patients, in the internal discal illness the symptoms had remained previous and after the surgery in $54 \%$, those with recurrent/ retained disc had had a bimodal distribution with $30 \%$ presenting worsening in six months and $48 \%$ in five or more years. Thus the time to symptoms return can guide for definitive causes of FBSS.

The surgical complications had been infection of the surgical wound in 6 patients, cerebrospinal fluid fistula in 2, and discitis in one patient. The main postoperative complaints had been radicular irritation signals, lumbago, paresthesias and muscular force reduction. Data that deserve attention were the occurrence of lumbar discal herniation to the left in $66.6 \%$ of the patients. We do not know if it has clinical relevance or if it only occurred accidentally. This had been repeated in the new surgical cases after the study.

There was only one diagnosis of psychiatric alteration. We believe that other comorbidity could have been diagnosed if had better inquiry under this aspect, therefore already it was demonstrated in some studies that the psychic and litigious factor possess great contribution for the FBSS 2,15 . Therefore when it will have imperfection in the treatment, we find that multidiscipline investigation must occur.

There are some attempts of classification of failed surgery syndrome, being one of them elaborated by Frymoyer and Cats-Baril ${ }^{16}$ in which is divided into four different subcategories based on a temporal probability scale: immediate failures, early recurrence, midterm failures and long term failures, thus allowing the orientation for the most likely cause. To include the patient correctly in a definitive pathology, it is important to know the concepts of each disease and they are very well described in the article of Slipman'.

A logical evaluation must be followed by the use of plain and flexion-extension X-ray, CT and MRI show the anatomical study and establish the diagnosis in the majority of the patients. The X-ray must be gotten in anteroposterior, lateral, oblique line and flexion/extension incidences. This technique demonstrates the anatomy and can be assessed disc space narrowing, facet joint arthritis and instability ${ }^{2}$. The CT demonstrates very well the osseo-anatomy, being more ideal to use the bi or three-dimensional reconstruction witch evaluates foraminal and spinal stenosis with precision. It can demonstrate disc alteration, but it is not useful for soft tissues neither for differentiating postoperative changes from recurrent or retained disc herniation ${ }^{2}$. The MRI does not show the bony anatomy well and stenosis is underestimated. It elucidates the intervertebral disc well, intradural structures and soft tissues, beyond differentiating fibrosis of recurrent hernia in the postoperative patient ${ }^{17}$.

Other complementary exams as ENMG, blockades anesthetics and discography are used when the diagnosis is not possible and appears doubts about the 
probable injury of the nerve, intervertebral disc or joint. The ENMG even in the root compression has accuracy that range between 20 and $90 \%$, and it becomes more difficult to interpreting in the postoperative, when other injuries can cause nerve irritation ${ }^{2}$. There are lacks of controlled studies about nervous root and the zygapophyseal joint blockade anesthetic and the specificities is not clear, beyond some authors thought that the existence of the facet syndrome must be questioned ${ }^{18}$. The used of discography for many services is also controversy, mainly when it is used in operated patients where up to $40 \%$ of the asymptomatic present positive test, and for the no-operated patient it must have an adequate election and follow the established criteria for positivity and injection pressure ${ }^{19,20}$.

The treatment is multi-functional, individualized, and depends on the correct diagnosis of the diverse possible causes. The occurrence of comorbidity as depression and anxiety develop due chronic pathology is an important factor that many times is forgotten, thus the treatment is not effective because the major concern is the anatomical disruption. It must be tried measured conservatives first, because $90 \%$ of all episodes of low back pain cases are nonsurgical. As general procedure, it is necessary to stimulate the loss of weight for the obese patient, guiding for the physiotherapy for a program of exercises, specific therapy and initial rest ${ }^{9}$. This adequate treatment usually is found in the chronic treatment centers of pain.

When it does not show any improvement, the next step is a surgical treatment. The surgical techniques used are laminectomy, discectomy, foraminotomy, arthrodesis, etc. Other therapeutical possibilities include the spinal dorsal stimulation whose results depends on the correct election of the patient, being those with arachnoiditis the most studied ${ }^{21,22}$. Epidural injections and injections on the nervous roots had been also very studied and they do not present good results $^{23,24}$. A study defends the preoperative irradiation for reoperation after epidural fibrosis with favorable results ${ }^{25}$, as also exist experiments with synthetic materials for the prevention of fibrosis ${ }^{26,27}$. The surgery is more indicated for the root compression processes and for column instability, because in other diseases the answers are not so satisfactory. Someone also defends cut the epidural fibrosis.

In conclusion, the FBSS remains a challenge for the surgeons as diagnostic aspect as in the treatment. The key point is to know which alteration is really caus- ing the patient aggression. Thus, a good history followed of adequate complementation diagnostic, establishes the cause in about $90 \%$ of the cases and so can prevent unnecessary surgeries and inefficacious treatments.

\section{REFERENCES}

1. Slipman $\mathrm{CW}$, Shin $\mathrm{CH}$, Patel RK, et al. Etiologies of failed back surgery syndrome. Pain Med 2002;3:200-214.

2. Long DM. Failed back surgery syndrome. Neurosurg Clin N Am 1991;2: 899-919.

3. Waguespack A, Schofferman J, Slosar P, et al. Etiology of long-term failures of lumbar spine surgery. Pain Med 2002;3:18-22.

4. Schofferman J, Reynolds J, Herzog R, et al. Failed back surgery: etiology and diagnostic evaluation. Spine J 2003;3:400-403.

5. Burton CV, Kirkaldy-Willis WH, Yong-Hing K, et al. Causes of failure of surgery on the lumbar spine. Clin Orthop 1981;157:191-199.

6. Talbot L. Failed back surgery syndrome. BMJ 2003;327:985-986.

7. Long DM, Filtzer DL, BenDebba M, et al. Clinical features of the failedback syndrome. J Neurosurg 1988;69:61-71.

8. Schwarzer AC, Aprill CN, Bogduk N. The sacroiliac joint in chronic low back pain. Spine 1995;20:31-37.

9. Hagen $\mathrm{KB}$, Jamtvedt $\mathrm{G}$, Hilds $\mathrm{G}$, et al. The update cochrane review of bed rest for low back pain and sciatica. Spine 2005;30:542-546.

10. Long DM. Management of persistent symptoms following lumbar disc surgery. In Schmidek HH, Sweet WH (eds). Operative neurosurgical techniques: indications, methods, and results. New York: Saunders, 1995:1935-1939.

11. Fritsch EW, Heisel J, Rupp S. The failed back surgery syndrome: reasons, intraoperative findings, and long-term results: a report of 182 operative treatments. Spine 1996;21:626-633.

12. Bernard TN Jr. Repeat lumbar spine surgery: factors influencing outcome. Spine 1993;18:2196-2200.

13. Kim SS, Michelsen CB. Revision surgery for failed back surgery syndrome. Spine 1992;17:957-960.

14. Larequi-Lauber T, Vader JP, Burnand B, et al. Appropriateness of indications for surgery of lumbar disc hernia and spinal stenosis. Spine 1997;22:203-209.

15. Pearce JM. Aspects of the failed back syndrome: role of litigation. Spinal Cord 2000;38:63-70.

16. Frymoyer JW, Cats-Baril WL. An overview of incidences and costs of low back pain. Orthop Clin N Am 1991;22:263-271.

17. Van Goethem JWM, Parizel PM, Jinkins JR. MRI of the postoperative lumbar spine. Neuroradiology 2002;44:723-739.

18. Schwarzer AC, Aprill CN, Derby R, et al. Clinical features of patients with pain stemming from the lumbar zygapophysial joints: is the lumbar facet syndrome a clinical entity? Spine 1994;19:1132-1137.

19. Carragee EJ, Alamin TF. Discography: a review. Spine J 2001;1:364-372.

20. Heggeness MH, Watters WC, Gray PM. Discography of lumbar disc after surgical treatment for disc herniation. Spine 1997;22:1606-1609.

21. North RB, Kidd DH, Piantadosi S. Spinal cord stimulation versus reoperation for failed back surgery syndrome: a prospective, randomized study design. Acta Neurochir 1995;64(Suppl):S106-S108.

22. Taylor RS, Van Buyten JP,Buchser E. Spinal cord stimulation for chronic back and leg pain and failed back surgery syndrome: a systematic review and analysis of prognostic factors. Spine 2004;30:152-160.

23. Sevulder J, Deene P, De Laat M, et al. Nerve root sleeve injections in patients with failed back surgery syndrome: a comparison of three solutions. Clin J Pain 1999;15:132-135.

24. Rocco AG, Frank E, Kaul AF. Epidural steroids, epidural morphine and steroids combined with morphine in the treatment os post-laminectomy syndrome. Pain 1989;36:297-303.

25. Gerszten PC, Moossy JJ, Flickinger JC, et al. Low-dose radiotherapy for the inhibition of peridural fibrosis after reexploratory nerve root decompression for postlaminectomy syndrome. J Neurosurg Spine 2003;99:271-277.

26. Lee HM, Yang KH, Han DY, et al. An experimental study on prevention of postlaminectomy scar formation. Yonsei Med J 1990;31:359-366.

27. Horenstein S. Chronic low back pain and the failed low back syndrome. Neurol Clin 1989;7:361-385. 